\title{
Diagnosis of Pemphigus associated with canine Leishmaniosis: a Case Report
}

\author{
Marilene da Silva Marques 1,2*,Érico do Nascimento Arruda 2, Aline Maia Silva 1 \\ ${ }^{1}$ Faculdade Terra Nordeste - FATENE, Ceará, CE, Brazil. \\ ${ }^{2}$ Vet World Clínica Veterinária, Ceará, CE, Brazil. \\ *Corresponding author: Marilene da Silva Marques. Rua Pereira Filgueiras, 1550 -Meireles, Fortaleza, $n^{\circ}$-District. \\ Zip Code: 60160-194-Ceará, CE, Brazil.. Phone: +55(85) 3104-5433. E-mail: marii.s.marques@hotmail.com.
}

Research Ethics Committee Approval (if necessary): Not applicable.

Received on: May 2, 2021. Accepted on: Mon 17, 2021. Available online: May 21, 2021.

\begin{abstract}
Pemphigus is an autoimmune dermatological condition that affects dogs and has in its clinical aspects a similarity to leishmaniasis, in which a differential diagnosis by means of histopathological examination is necessary. The present study sought to report a case of a dog, male, mixed breed, 10 years old, diagnosed with pemphigus and, later, diagnosed with leishmaniasis. Upon diagnosis, the animal presented only a lesion in the nasal plane, without apathy and without systemic changes, as evidenced by hematological and biochemical tests. After performing histopathological examination, the animal was diagnosed with pemphigus and underwent immunosuppressive treatment, obtaining significant improvement of the lesion. Under clinical suspicion of leishmaniasis, the animal was subjected to serological exams RIFI and ELISA resulting in an indeterminate result in ELISA and 1/40 reagent in the RIFI. As this is not a very relevant result, it was decided to perform another histopathological examination of the lesion where the presence of Leishmania spp. In this new exam it was not possible to obtain a diagnosis of pemphigus again, since the animal was under immunosuppressive treatment. Therefore, it is concluded that, in cases of co-infection of autoimmune diseases, such as pemphigus and canine leishmaniasis, the differential diagnosis by means of histopathological examination is extremely relevant to the patient's therapeutic success and prognosis. Thus, it is necessary to note that the diagnosis of pemphigus does not exclude the diagnosis of leishmaniasis.
\end{abstract}

Keywords: Pemphigus; Leishimaniasis; Histopathological.

\section{Introduction}

Veterinary dermatology is an area that has been growing in recent years, and the diagnosis and treatment of skin changes have represented about 30 to $75 \%$ of visits to the veterinary clinic [1]. This high prevalence is due to the fact that skin problems attract attention and cause some disgust, leading the owner to seek veterinary assistance for his animal [2].

Immune skin diseases are divided into autoimmune and immunemediated. Immune - mediated 
dermatoses appear to result from an immunological event that does not act directly against auto-antigens, the skin not being the primary antigen [3]. However, autoimmune diseases result from the production of antibodies and / or the activation of lymphocytes against the skin's own components [4].

Autoimmune dermatoses are considered uncommon in dogs and cats, representing $2 \%$ of the dermatological diagnosis in small animals [5]. Among these diseases, we can mention the pemphigus complex, which is a vesicobullous or pustular dermatological condition, being the most common among autoimmune diseases [4].

There are currently four variants of Pemphigus: foliaceous, vulgar, erythematous and vegetative, pemphigus foliaceus being the most common among them [3]. This condition can affect several species, being more frequent in dogs [6]. The disease is characterized by the appearance of pustular, scaly and ulcerative lesions on the face, nasal plane, nostril, periocular and pinna [7].

The diagnosis of Pemphigus is based on anamnesis data, symptomatic aspects and mainly through histopathological examination [3, 8-9]. The treatment of Pemphigus is immunosuppressive with the aid of glucocorticoids orally and in nonresponsive cases, cytostatic drugs such as azathioprine can be used [10]. The treatment requires long periods, having cases in which it is necessary for a lifetime, besides that it can influence the triggering of other pre-existing diseases [3].

The etiology of pemphigus has not been well described, but it may have idiopathic characteristics or it may be secondary to the use of certain medications, chronic diseases, exposure to sunlight and ultraviolet light $[3,11]$, neoplasms, emotional and nutritional factors, hormonal or even viral infections [12], insect bites [13], in addition to factors related to the animal, such as race, genetics, predisposition to allergies, and having other diseases such as systemic lupus erythematosus and leishmaniasis [11].

In view of the low prevalence of this disease and because it was initially confused with other pathologies, the present study aimed to report the case of a 10-year-old male, male, mestizo dog diagnosed with pemphigus and subsequently diagnosed with leishmaniosis.

\section{Case report}

A 10-year-old male, mixed breed, canine animal, weighing $15 \mathrm{~kg}$, not neutered, domiciled and vaccinated (rabies and multipurpose vaccines) was assisted in a private veterinary clinic with an old nasal lesion (more than 6 years) and progressive, associated with skin lesions on the tail, back and head.

In the anamnesis, complete physical examination, palpation of 
lymph nodes, capillary filling time, measurement of rectal temperature, cardiac and pulmonary auscultation, measurement of mucosal staining, inspection of hair and skin, bladder and abdominal palpation were performed.

During the physical examination, an ulcerative lesion was found in the nasal mirror (Figure 1A), in which the two orifices were obstructed, making it difficult to breathe, in addition to alopecia in the syrup region (Figure 1B, B) and head (Figure 1C), however, this alopecia was not accompanied by ulcers or suppuration and the animal did not have itching. Upon palpation of the lymph nodes, no reactive lymph node was found.

On auscultation, no cardiac abnormalities were observed, with normal rectal temperature, normalcolored oral mucosa, and hyperemic ocular mucosa with the presence of uveitis. The animal was alert, active and without physiological changes.
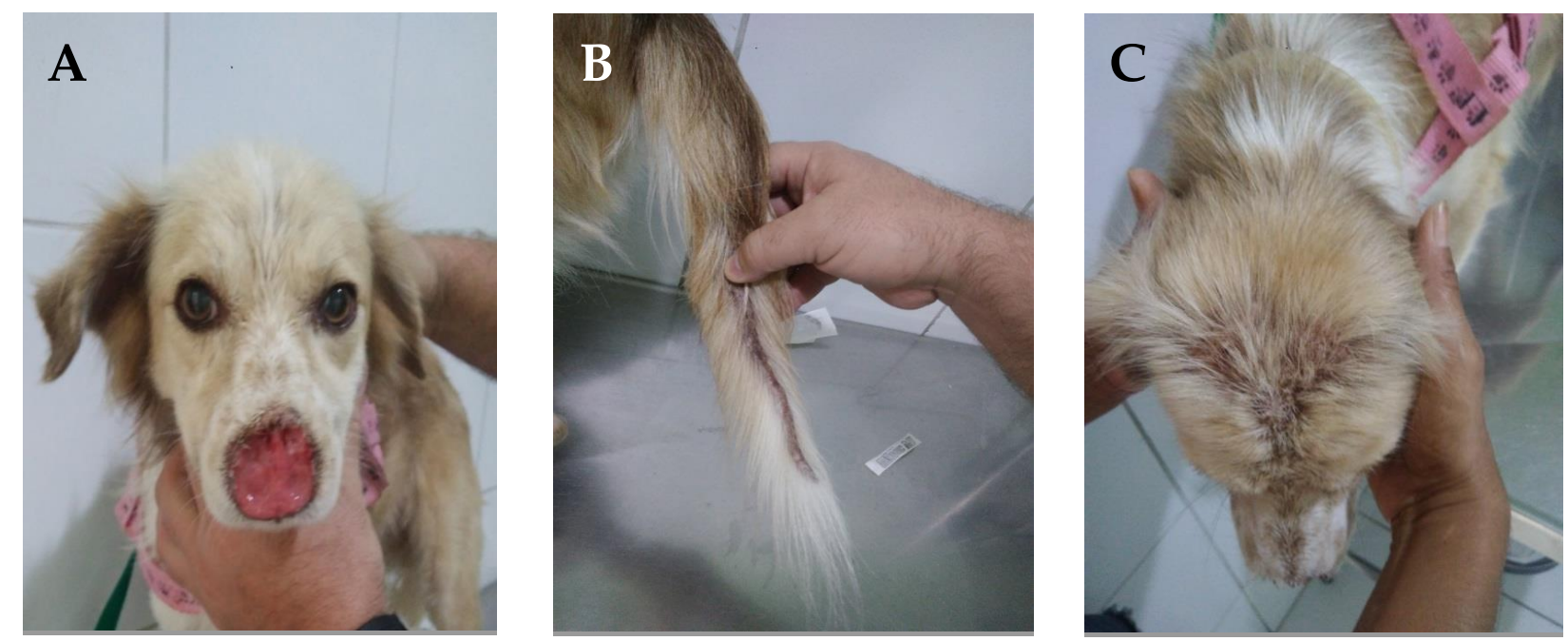

Figure 1. A. Lesion on the nasal mirror. B. and C. Tail and head alopecia.

The animal underwent full blood and biochemical laboratory tests (ALT and Creatinine), with normal results. In addition, serology was performed for leishmaniasis by Indirect Immunofluorescence Reaction (RIFI), Elisa (total dilution) and biopsy for histopathological analysis of the lesion for the purpose of clinical investigation for Pemphigus. Histopathological examination was positive for Pemphigus.
Laboratory tests were found to be within normal parameters, with indeterminate results from the ELISA and reagent in $1 / 40$ on the RIFI, not confirming positivity for Leishmaniasis. The following therapeutic protocol was administered: Prednisolone 20mg (1.3 $\mathrm{mg} / \mathrm{kg}$, for 14 days); Marbopet ${ }^{\circledR}$ $82.5 \mathrm{mg}$ (1/2 tablet once daily for 40 days) and Allopurinol 100mg (2 tablets every 12 hours until reevaluation), due to the suspicion of a clinical picture of canine Leishmaniasis. 
After the therapeutic protocol, the animal was reevaluated and a positive result was identified for the instituted treatment, with regression of the lesion being visualized, with apparent granulation tissue and airway clearance (Figure 2A), allowing the animal to breathe better.

Treatment with Prednisolone and Allopurinol was prolonged for another month, continuing at the same dose. After the end of the new therapeutic period, the animal returned for evaluation, being asked for a new histopathological examination of the nasal lesion for the purpose of investigating the diagnosis of Leishmaniasis. Under sedation (3 $\mathrm{mg} /$ $\mathrm{kg}$ of Propfol and $2 \mathrm{mg} / \mathrm{kg}$ of Ketamine were administered), a new biopsy was performed for examination.

The animal was released with a new prescription: Prednisolone 20mg (1 tablet and a half every 24 hours for 21 days) and continued with the use of



Allopurinol, until the biopsy result was obtained.

The result of the new histopathological examination diagnosed the presence of amastigote forms of Leishmania spp. in the nasal tissue sample. It was assessed that the animal continued to respond more and more positively to treatment with corticosteroids, with improvement of the lesion in the nasal plane (Figure 2B), being informed that the animal was eating well and was always active.

In view of the result of the histopathological examination, the veterinarian chose to wean the corticoid with administration of half a tablet daily for 7 days and instructed the guardian that the animal should continue the treatment with Allopurinol, also beginning the use of Milteforan and you should use a repellent collar.

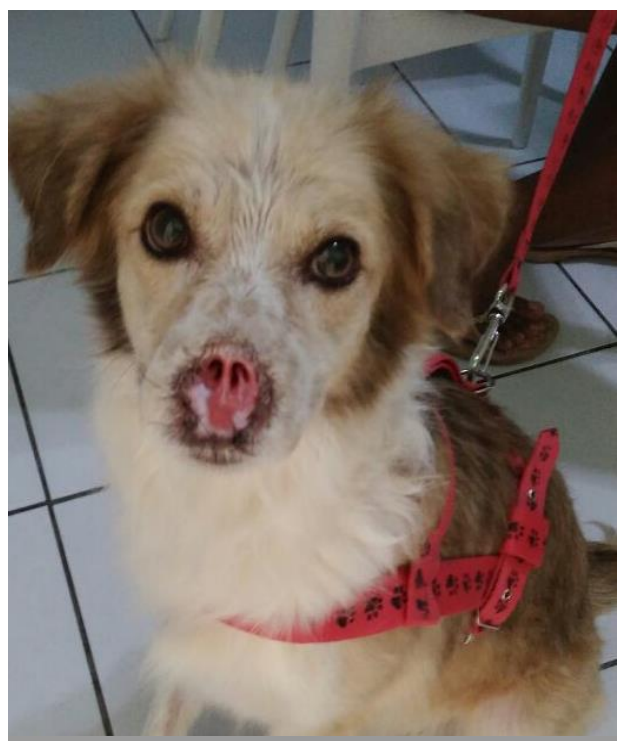

Figure 2. A. and B. Recovery of the animal's nasal lesion after treatment sections. 


\section{Discussion and Conclusion}

The case of the canine patient presented in the present study shows that it does not have any of the breeds most affected by pemphigus, which are Akita, Chow Chow, Dachshund, Dobermam, Poodle, Newfoundland, Labrador Retriever, Pinscher and Collie $[6,8,10]$. The canine reported here is in the age group where high levels of pemphigus are reported $[10,14]$.

Dogs with pemphigus foliaceus have very ephemeral pustular lesions, which are primary and rarely seen. In most animals what can be observed are secondary lesions such as papules, crusts, scales, epidermal collars resulting from pustular rupture, ulcers and alopecia $[3,4,8]$.

Pemphigus vulgaris, on the other hand, affects the oral cavity, mucocutaneous junctions and skin, with painful bullous, erosive and / or ulcerative vesicles, with a hemorrhagic background and irregular borders [3]. Simultaneously to the dermatological signs, some dogs may present lymphadenopathy, fever, pain, itching, anorexia and depression [15].

In this case, the animal presented only a single ulcerative lesion with a hemorrhagic fundus in the nasal plane region in which he demonstrated pain, in addition to difficulty breathing due to upper airway obstruction. In the histopathological exam that diagnosed pemphigus, it was not described what type of pemphigus would be.

Histopathological examination is the method of choice to close diagnosis of pemphigus $[3,6,10,16]$, in which there is layer acantholysis suprabasal or sub-corneal bed of the epidermis resulting in cracks, which are clinically portrayed by the formation of vesicles or pustules.

The pustule contains neutrophils, eosinophils and acanthocytes [3, 4, 6, 10]. In this case, the animal arrived with a histopathological report with diagnosis for pemphigus, where the following observation was described: "the skin section shows irregular, hyper and paraceratotic acanthosis of the epidermis, with multiple areas of spongiosis, which sometimes form bubbles and cracks in the basal layer interspersed with lymphocytes, seen especially in regions of the ulcer border from an intense inflammatory process. Pigmentary incontinence. Hemorrhagic foci. No parasites were found". Therefore, according to what is described in the literature.

Immunosuppression with systemic glucocorticoids remains the main therapeutic choice [17]. The form of therapy chosen will depend on the individual response and the patient's side effects. But commonly, prednisone or prednisolone, taken orally, is used in an immunosuppressive dose, starting at 2.2 - $4.4 \mathrm{mg} / \mathrm{kg}$ every 24 hours, and if there is a positive response from 10 to 14 days, the dose is gradually reduced over 30 to 40 days, and then administered on 
alternate days, as the ultimate goal is to reach a dose of $1 \mathrm{mg} / \mathrm{kg}$ every 48 hours or less $[6,9]$.

In the aforementioned case, prednisolone $20 \mathrm{mg}$ ( 1 tablet once a day, for 14 days) was instituted as follows; marbopet ${ }^{\circledR} \quad 82.5 \mathrm{mg} \quad(1 / 2$ tablet once daily for 40 days) and allopurinol $100 \mathrm{mg}$ (2 tablets every 12 hours until reevaluation), as leishmaniasis was also suspected. After 15 days the animal returned for evaluation showing a positive result and the treatment with corticosteroids was prolonged for another month. After this period, treatment was continued with an increase in the dose of prednisolone $20 \mathrm{mg}$ ( 1 tablet and a half every 24 hours for 21 days) and the use of allopurinol $100 \mathrm{mg}$ continued.

After 21 days the animal was reevaluated and showed a very significant improvement. When leishmaniasis was suspected, a serological RIFI and ELISA test (total dilution) was performed, which resulted in: ELISA: indeterminate and RIFI: 1/40 reagent. According to Alves and Bevilacqua (2004), results below 1/80 need confirmation through other methods.

The result that confirmed the presence of leishmaniasis in the animal started from the histopathological exam that was requested again where it showed the presence of amastigost forms of Leishmania spp. in macrophage cytoplasm, and the pemphigus result was no longer demonstrated in this new exam, however the animal was under treatment with corticosteroids for 45 days $[4,6,18]$.

The primary lesion and the intact pustule are ideal to be assessed at histopathological examination for the diagnosis of pemphigus $[4,6,18]$. However, the second collection of material for the histopathological examination cannot be performed on primary lesions, as there were no pustules. The first histopathological examination was carried out in another location and the tutor was unable to describe what the injury was like at the time.

According to Scott; Miller; Griffin [3] and Lucarts [11], pemphigus may be related to chronic diseases such as Leishmaniasis. In this case, it is not known for sure whether the animal first acquired leishmaniasis and then pemphigus or vice versa, but we can say that the presence of one does not exclude the other.

In a study conducted in human medicine reports that in patients diagnosed with American cutaneous leishmaniasis, antibodies against desmogleins 1 and 3 were found, considering that antigens from the saliva of leishmaniasis-transmitting insects that could trigger the formation of these antibodies [19].

In a study carried out in Tunisia, it was determined that the prevalence of 
anti-Dsg1 antibodies was higher in individuals with Cutaneous Leishmaniasis, suggesting that the persistent exposure to Phlebotomus papatasi, which is the sandfly responsible for the transmission of the disease in that region, must have a relationship with pemphigus, and the direct implication of the parasite Leishmania spp. must be considered [20].

Based on this information, we can consider that Leishmaniasis may have led the patient to develop pemphigus. In summary, the present case report demonstrates that, in cases of coinfection of autoimmune diseases such as pemphigus and canine leishmaniasis, the differential diagnosis by means of histopathological examination is extremely relevant to the therapeutic success and prognosis of the patient. Thus, it is necessary to note that the diagnosis of pemphigus does not exclude the diagnosis of leishmaniasis.

\section{References}

[1] Pinho R, Monzón MF, Simões J. A pele e seus aspectos relevantes na pratica clínica. Dermatologia Veterinária em animais de companhia. 2013, 5(1).

[2] Souza TM, Fighera RA, Irigoyen, LF, Barros CSL. Estudo retrospectivo de 761 tumores cutâneos em cães. Ciência Rural. 2006, 36(2):555-560.

[3] Scott DW, Miller DH, Griffin CE. Muller \& kirk's Small Animal
Dermatology, 6 ed. Philadelphia: Saunders, 2001.

[4] Costa-Val A. Doenças cutâneas autoimunes e imunomediadas de maior ocorrência em cães e gatos: revisão de literatura. Revista Clínica Veterinária. 2006, 60:68-74.

[5] Hill PB, Lo A, Eden CA, Huntley S, Morey V, Ramsey S, Richardson C, Smith DJ, Sutton C, Taylor MD, Thorpe E, Tidmarsh R, Williams V. Survey of the prevalence, diagnosis and treatment of dermatological conditions in small animals in general practice. Vet Rec. 2006 Apr 22;158(16):533-9.

[6] Rosenkrantz WS. Pemphigus: current therapy. Vet Dermatol. 2004 Apr;15(2):90-8.

[7] Gomez SM, Morris DO, Rosenbaum MR, Goldschmidt MH. Outcome and complications associated with treatment of pemphigus foliaceus in dogs: 43 cases (1994-2000). J Am Vet Med Assoc. 2004 Apr 15;224(8):1312-6.

[8] Larsson CE. Sinais dermatológicos clássicos na medicina veterinária. Brazilian Journal of Veterinary Research and Animal Science. 2014, 51(1):6-16.

[9] Medleau L, Hnilica KA. Doenças autoimunes e imunomediadas. In: Dermatologia de pequenos animais, atlas colorido e guia terapêutico. 2 ed. Editora: Roca, 2009.

[10] Balda AC, Ikeda MO, Larsson Junior CE, Michalany NS, Larsson CE. Pênfigo foliáceo canino: estudo retrospectivo de 43 casos clínicos e 
terapia (2000-2005). Pesquisa Veterinária Brasileira. 2008, 28(8):387-392.

[11] Lucarts LEB. Avaliação de exequibilidade e da efetividade da avaliação de anticorpos séricos pela IFI, em cães acometidos pênfigo foliáceo na pré e trans-terapia. 2010. 89pg. Dissertação (Mestrado em clínica medica) - Faculdade de Medicina veterinária e zootecnia, Universidade de São Paulo, São Paulo.

[12] Brenner S, Sasson A, Sharon O. Pemphigus and infections. Clinics in Dermatology. 2002, 20:114-118.

[13] Aoki V, Rivitti EA, Ito LM, HansFilho G, Diaz LA. Perfil histórico da imunopatogenia do pênfigo foleáceo endêmico (fogo selvagem). Anais Brasileiros de Dermatologia. 2005, 80(3): 287-292.

[14] Rhodes KH, Werner AH. Dermatologia em pequenos animais. 2. ed. São Paulo: Roca, 2014.

[15] Graig M. Disease facts: pemphigus foliaceus in the dog e cats. Companions animal. 2013, 18(8):374-377.

[16] Larsson CE. Sinais dermatológicos clássicos na medicina veterinária. Brazilian Journal of Veterinary Research and Animal Science. 2014, 51(1):6-16.

[17] Ruocco V, Ruocco E, Wolf R. Bullous diseases: unapproved treatments or indications. Clinics in Dermatology. 2000, 18:191-195.

[18] Werner AH. Recognizing and treating discoid lupus erythematous and pemphigus foliaceus in dog. Veterinary Medicine. 1999, 94:955-966.

[19] Santos PVWG. Relação imunogênica dos pênfigos com a leishmaniose tegumentar. Tese (Doutorado) - Faculdade de Medicina de Ribeirão Preto da Universidade de São Paulo, 2015.

[20] Rocha OS, Santos OLR. Aspectos etiológicos e epidemiológicos do pênfigo foliáceo endêmico (fogo selvagem). RBM Dermatologia e cosmiatria. 2015, 72.

Conflict of interest: The author declares no conflicts of interest.

\section{Acknowledgements: None.}

Funding: None.

How to cite this article: Marques MS, Arruda EM, Silva AM. Diagnosis of Pemphigus associated with canine Leishmaniasis: a Case Report. Brazilian Journal of Case Reports. 2021 AbrJun;01(2):45-52. 